Review / Derleme

\title{
Surgical treatment in malignant pleural effusion
}

\author{
Malign plevral efüzyonda cerrahi tedavi
}

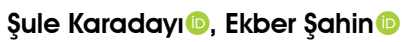

Department of Thoracic Surgery, Medicine Faculty of Cumhuriyet University, Sivas, Turkey

\begin{abstract}
Malignant pleural effusion can be described as the presence of exudate in the pleural space, accompanied by the detection of cancer cells in pleural fluid or tissue, which is the indicator of the disease in its advance stages, and survival time of these patients ranges between 3 and 12 months. Treatment options for malignant pleural effusion vary from observation in asymptomatic patients to pleurectomies or even extrapleural pneumonectomies in severe cases.
\end{abstract}

Keywords: Malignancy, pleural effusion, pleural metastasis, pleurectomy, tunneled pleural catheter.

Malignant pleural effusion (MPE) is defined as the large quantity of exudate in the pleural space, which is accompanied by the presence of cancer cells in pleural fluid or tissue. It can be a result of primary pleural malignancies, mainly mesothelioma, or extrapleural malignancies caused by metastases in the pleura. Other mechanisms for malignant pleural involvement include direct pleural invasion from adjacent tumors in the lungs, breasts or chest wall. At the time of the initial diagnosis of the effusion, patients with MPE up to $10 \%$ have an unknown primary location. ${ }^{[1-3]}$ In developed countries, MPE is categorized as the third common cause of pleural effusion following heart failure and parapneumonic effusion ${ }^{[1,2]}$ It indicates the presence of advanced malignant disease, and survival time of these patients ranges between three and 12 months. ${ }^{[1]}$

Pleural effusions in patients having a known malignancy that do not have malignant cells in the pleural cavity are called paramalignant effusions.

\section{$\ddot{O} Z$}

Malign plevral efüzyon, plevral sıvı veya dokuda kanser hücrelerinin saptanması ile birlikte plevral boşlukta önemli miktarda eksüdat birikmesi olarak tanımlanır. İlerlemiş hastalığın bir göstergesidir ve sağkalım süresi 3 ila 12 ay arasında değişir. Malign plevral efüzyon için tedavi seçenekleri asemptomatik hastalarda gözlemden ağır hastalarda plörektomi ve hatta ekstraplevral pnömonektomiye kadar değişkenlik gösterir.

Anahtar sözcükler: Malignite, plevral efüzyon, plevral metastaz, plörektomi, tünelli plevral kateter.

Paramalignant effusions occur due to malignancy, but not due to tumor invasion into the pleura. Instead, they are the result of indirect effects of the tumor, as bronchial obstruction, post-obstructive pneumonia, lymphatic obstruction, thromboembolism, vena cava superior syndrome, hypoalbuminemia, and certain forms of cancer treatment. ${ }^{[1,2]}$

Pleural effusion occurs as a result of the increase in the fluid production or decreased lymphatic clearance or a combination of both. Under normal conditions, it is extremely difficult to accumulate excess fluid in the pleural cavity, as the absorbability capacity of the pleural fluid is 28 times higher than the rate of its production. ${ }^{[4]}$

Before the pleural fluid passes into the pleural space, systemic capillaries, pleural interstitium and pleural membrane must pass. While the distance between the intercostal arteries that provide blood to the parietal pleura and the pleural membrane

Received: August 07, 2020 Accepted: October 23, 2020 Published online: October 20, 2021

Correspondence: Şule Karadayı, MD. Cumhuriyet Üniversitesi Tıp Fakültesi, Göğüs Cerrahisi Anabilim Dalı, 58140 Sivas, Türkiye.

Tel: +90 505 - 5025186 e-mail: sulekaradayi73@yahoo.com

Karadayı Ş, Şahin E. Surgical treatment in malignant pleural effusion. Turk Gogus Kalp Dama 2021;29(4):577-585 
is 10 to $12 \mu \mathrm{m}$, and the distance to the bronchial arteries that provide blood to the visceral pleura is 20 to $50 \mu \mathrm{m}$. In addition, since the filtration pressure of the intercostal arteries is higher than the filtration pressure of the bronchial arteries and the parietal pleura is thinner than the visceral pleura, most of the fluid is thought to originate from the parietal pleura. Therefore, the most effective surgical target for controlling an MPE appears to be the parietal pleura. ${ }^{[1-5]}$

In MPE, pleural fluid can be serous, serohemorrhagic or hemorrhagic. While gross bloody effusions are suggestive of direct pleural involvement, serous effusions develop due to the increased lymphatic permeability and are typically exudative. The protein concentrations range from 1.5 to $8 \mathrm{~g} / \mathrm{dL}$, but can be up to $5 \%$ transudate. These transudative effusions may be due to early stages of lymphatic obstruction, bronchial obstruction-related atelectasis, or concomitant diseases such as congestive heart failure..$^{[1-3]}$

\section{Etiology}

Malignant pleural effusion can be listed among the most common causes of cancers of the lung, and the pleura may be involved by direct extension or by vascular embolization. Among solid tumors, cancer of the breast is among the second most common cause of MPE (accounting for approximately 25\% occurrence rate; Table 1). ${ }^{[2]}$ A number of factors related to poor prognoses of MPE have been identified such

\section{Table 1. Etiology of MPE}

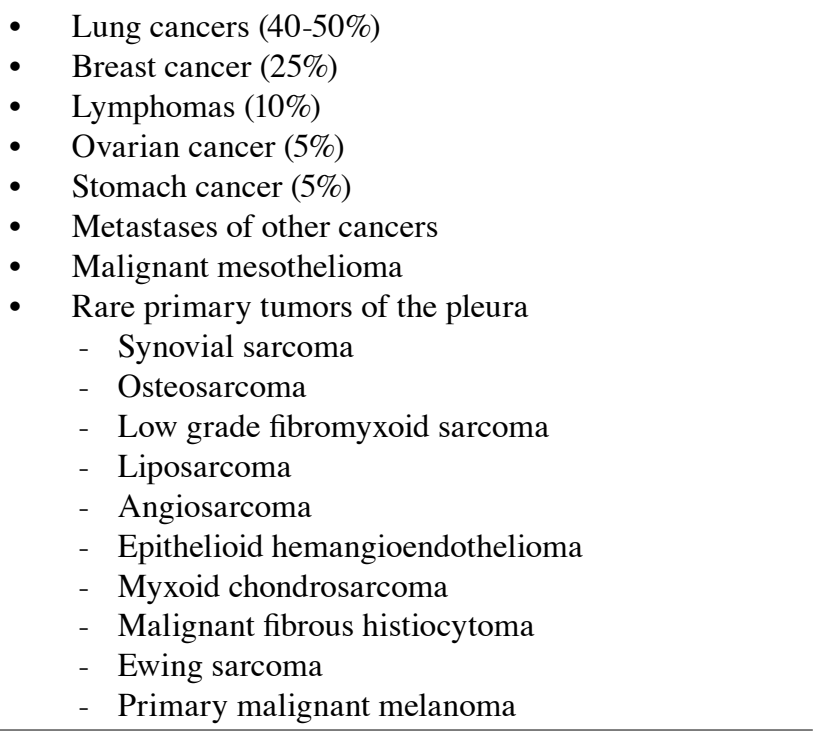

MPE: Malignant pleural effusion. as pleural fluid with low $\mathrm{pH}$ and low glucose levels, hypoalbuminemia, hypoxia, and leukocytosis. ${ }^{[6]}$ Clive et al. ${ }^{[7]}$ evaluated MPE in 789 patients and classified the variables of Eastern Cooperative Oncology Group (ECOG) performance score, pleural fluid lactate dehydrogenase, blood neutrophil-to-lymphocyte ratio, and tumor type among the criteria of the prognosis. They also identified and derived a risk classification system called the "LENT" score (named after these four factors), where a score of $0-1$ indicates a reduced risk, 2-4 indicates a mild risk, and 5-7 indicates an increased risk. ${ }^{[7]}$

\section{Therapeutic Strategies for MPE}

General, MPEs are not required to be treated, as long as they remain asymptomatic; however, almost all malignant effusions become symptomatic. Treatment options for MPE range from observation in asymptomatic patients to pleurectomies or even extrapleural pneumonectomies (EPP) in severe cases (Table 2). There are various treatment options and decisions pertaining to the type of the treatment method which needs to focus on the size of the effusion, the rapidity of its reaccumulation, the symptoms that arise, whether there is the presence of a trapped lung, the expected survival (depending on the primary malignancy type and performance status and comorbidities of the patient), and the preference of the patient. It is of due significance to reduce the length of the patient's hospital stay by using recurrent thoracentesis or inserting a tunneled pleural catheter in patients with a poor prognosis. ${ }^{[1,2]}$

The main treatment goals for MPEs are to achieve fluid control, improve patient's symptoms, offer a good quality of life, be well tolerated by the patient, low cost, minimally invasive, and lead to notable reductions in the length of stay in the hospital. However, for MPE patients who are not eligible for surgery, the goal of treatment should be lung re-expansion. If the re-expansion of the lungs cannot

\section{Table 2. Treatment methods for MPE}

- Thoracentesis

- Tube thoracostomy

- Pleural catheter with tunnel

- Pleuroperitoneal shunt

- Drainage and pleurodesis

- Pleurectomy

- Extrapleural pneumonectomy

MPE: Malignant pleural effusion. 
be attained, there may be endobronchial obstruction or direct malignant involvement of the visceral pleura. If treatment respond can be attained, the associated effusion can resolve/remain stable. To illustrate, for the lung cancer with epidermal growth factor receptor (EGFR)-mutations, small-cell lung carcinoma, lymphoma and cancer of breast and ovary, well response to chemotherapy may be achieved

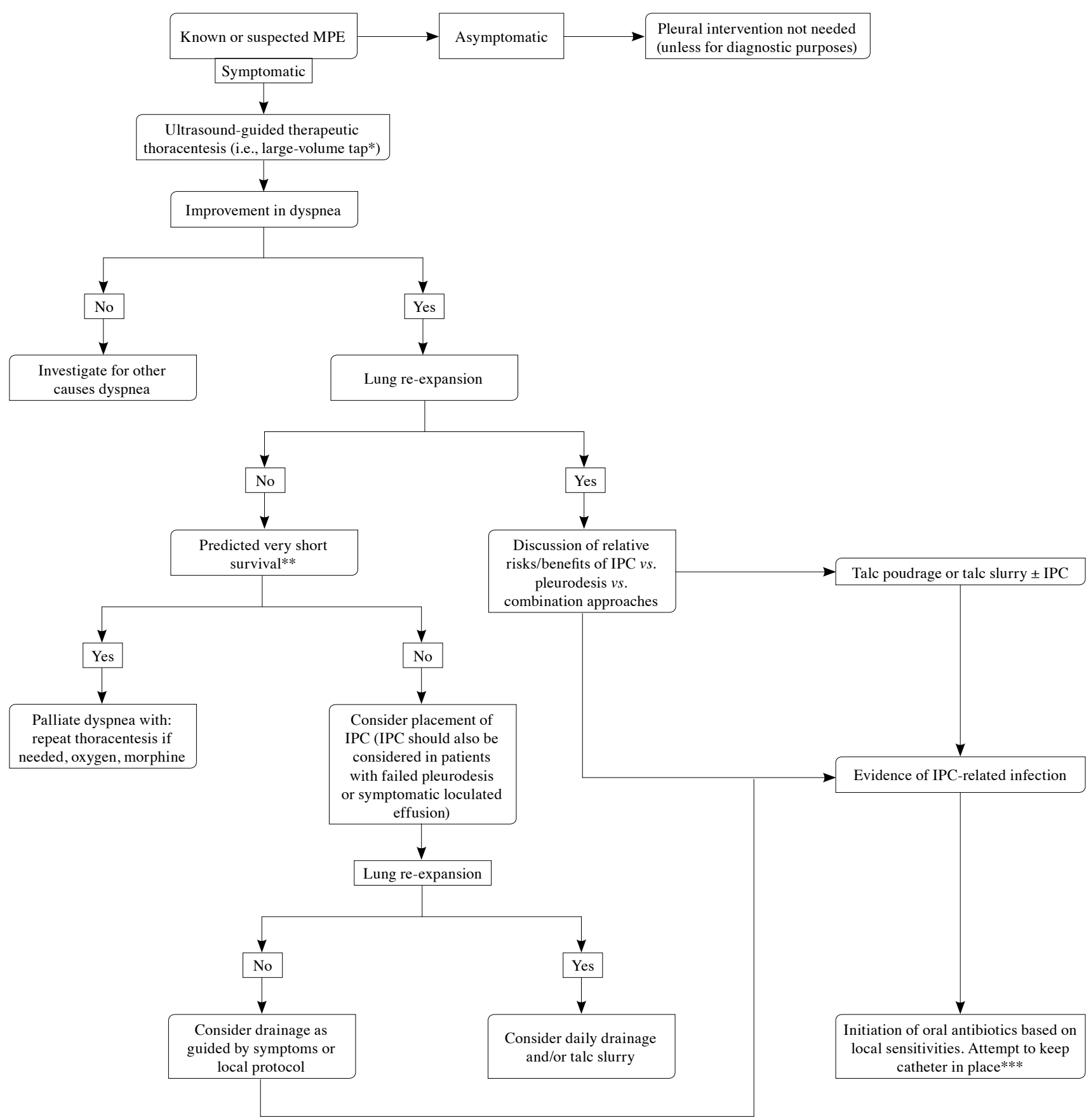

Figure 1. Treatment Algorithm of American Thoracic Society in Malignant Pleural Effusion.

MPE: Malignant pleural effusion; IPC: Indwelling pleural catheter; * With goals of assessing lung expansion and relief of dyspnea. This step may not be necessary if the patient's dyspnea is known to be attributable to the MPE; ** Physicians are not great predictors of prognosis. As such, the recommendation of "Predicted very short survival" should be used as a rough guideline and individualized on a case-by-case basis; *** Note: there is a low likelihood (2-4\%) of IPC-related infection. Escalation of care (intravenous antibiotics, hospital admission, removal of catheter) should be made on a case-by-case basis and is recommended if there are an signs/symptoms of worsening infection 
and measures to prevent fluid recurrence may not be necessary. ${ }^{[1,2]}$ The treatment algorithm of the American Thoracic Society (ATS) in MPE is shown in Figure 1.

\section{Therapeutic thoracentesis}

The main aim of a therapeutic thoracentesis is to relieve dyspnea. However, rapid and abundant discharge of pleural fluid can cause re-expansion pulmonary edema. Although it is not exactly known that how much fluid can be safely removed, it is usually recommended that $<1.5 \mathrm{~L}$ should be aspirated in a single sitting. If there is no significant improvement in dyspnea despite adequate fluid drainage by thoracentesis, other causes should be considered, such as underlying lung parenchymal disease, endobronchial obstruction, pulmonary embolism, and lymphangitis carcinomatosis. On condition that relief can be provided for dyspnea by therapeutic thoracentesis and lung expansion can be ensured before the fluid re-accumulates and symptoms rapidly return, a chest tube is inserted and a sclerosing agent is given..$^{[1,2]}$

\section{Tube thoracostomy and pleurodesis}

Pleurodesis refers to inducing the adhesion of both pleura to each other and is often considered in patients with symptomatic effusion with a reasonable life expectancy. On the other hand, if drainage from the chest tube is excessive or if there is the presence of a trapped lung, the pleurodesis procedure would not be successful as the pleural surfaces must touch each other. ${ }^{[8]}$ Although various methods of creating pleurodesis have been used, there is no consensus on the ideal approach. Surgical pleurodesis (e.g., mechanical abrasion) and bedside intrapleural instillation of chemical agents have been attempted; however, all the methods involve injuring the pleura, leading to intense inflammation and fibrosis.

Possible pleurodesis agents include sterile talc, tetracycline, chemotherapeutic agents (such as doxycycline, bleomycin and minocycline), betadine, hydrogen peroxide, and hypertonic saline. Talc is usually accepted as the most potent pleurodesis agent available, and randomized trials have shown no significant differences in successful pleurodesis outcomes whether talc is delivered as thoracoscopic poudrage or as slurry via a chest tube. ${ }^{[1,9]}$ Fever and pain are common after pleurodesis, and talc pleurodesis associated complications can be listed as acute pneumonitis, acute respiratory distress syndrome, hypoxia, respiratory failure, and death..$^{[1,8,10-12]}$ Talc pleurodesis fails in 30 to $50 \%$ of patients, but recurrent pleurodesis can be performed with the same agent or different ones. ${ }^{[1]}$

\section{Indwelling pleural catheter (IPC)}

The IPCs are one of the new methods used to treat the symptoms of patients with MPE. These are 15.5 to $16-\mathrm{F}$ silicone catheters with a fenestrated proximal end that is placed within the pleural cavity and a one-way valve at the distal end. They can be also used in ambulatory patients and allow intermittent pleural drainage. They are a good option for patients with failed pleurodesis and trapped lungs, ${ }^{[1]}$ and the current data supports their use as the MPE's first-line therapy in place of pleurodesis..$^{[1,10,13-15]}$

Spontaneous pleurodesis develops in up to $70 \%$ of patients with IPCs previously having full lung expansion, following which the IPC can be removed. ${ }^{[1,15,16]}$ Complications after the use of IPCs are rare $(\sim 12 \%)$ and, mostly, minor (e.g., cellulitis, catheter blockage, and IPC-related pleural infection). Catheter tract metastases develop in about $10 \%$ of patients (more commonly in mesothelioma patients) and can be controlled with radiotherapy. ${ }^{[1,16,17]}$

\section{PLEUROPERITONEAL SHUNT (PPS)}

A PPS consists of a couple of catheters that are inserted in the cavities of pleura and peritoneum and connected by a one-way valve pump chamber. When compressed, the pump transfers fluid from the pleura into the peritoneum. A PPS is likely to be used as an alternative to pleurodesis in patients with a trapped lung or following failed pleurodesis, which may yield effective palliation in patients with a rate of $95 \%$, although the emergence of some complications, particularly occlusion, can have a high incidence rate $(\sim 25 \%)$ and shunt revision, removal and/or replacement is often required. The need for PPSs has significantly decreased with the advent of IPCs. ${ }^{[1,18,19]}$

\section{Pleurectomy}

A parietal pleurectomy can be performed via a thoracoscopy or thoracotomy and is almost always effective at controlling the recurrence of the effusion. The most optimal results are obtained when the primary lesion is a carcinoma of the breast or a malignant mesothelioma, and the results are often worse in patients with a lung carcinoma. Complications such as empyema, hemorrhage or cardiovascular failure are frequent (as high as 34\%), and mortality rates are significant, with in-hospital rates of up to $9 \%$ and a three-month all-cause mortality rate of $17 \% .^{[2]}$ When lung decortication is necessary as a complementary 
procedure of the pleurectomy, the complication rate approaches $70 \%$ with a postoperative mortality rate of $20 \% .^{[2]}$ Therefore, this procedure should only be performed with a patient group with high eligibility, such as those not responding to chemical pleurodesis, with an expectancy of life over half a year and in an overall good condition. ${ }^{[2]}$

In a study conducted by Kara et al., ${ }^{[8]} 19$ MPE patients who did not respond to other conventional treatment procedures underwent thoracoscopic pleurectomies from a single port. The patients had a variety of such malignancies as cancers of lung, breast, stomach, renal cell and lymphoma. No complications, morbidity or mortality were observed after the pleurectomy procedure, and the overall success rate was $91.4 \%$. As this rate is better than that of thoracoscopic talc powder, the authors recommended pleurectomy with uniportal video-assisted thoracic surgery (VATS) as the optimal pleurodesis method for MPE patients.

\section{Surgical treatment according to primary tumor Malignant pleural effusion in lung cancer}

Nearly $50 \%$ of all lung cancer patients have malignant pleural effusion and their prognosis tends to be worse than those of patients with no MPE..$^{[1,20]}$ A study conducted by the International Association for the Study of Lung Cancer (IASLC) Lung Cancer Staging Project examined 771 patients with non-small-cell lung carcinoma and MPE and found that the patients had an avarage survival of 10 months and only $2 \%$ had a five-year survival rate, leading to the reclassification of MPEs as M1a or Stage IV in the $7^{\text {th }}$ edition of the Tumor, Node, Metastasis (TNM) staging system. ${ }^{[21]}$ MPE patients and other distant metastases (M1b) had a median survival of only three months, while the median survival was five months for M1b without MPE. ${ }^{[22]}$ Trapped lung is frequently seen in cancers of lung, in which pleurodesis is contraindicated and the most appropriate treatment option is an IPC. ${ }^{[1]}$

Lung adenocarcinoma constitutes the most common cell type with the pleura. In autopsies on lung cancer patients with MPE, metastases were detected on the surfaces of visceral and parietal pleural. The involvement of isolated visceral pleural involvement was rare and isolated parietal pleural metastases were never encountered. The mechanism of action of visceral pleural metastases in lung cancer is most likely proximal spreading or peripheral vascular embolization of the tumor. Malignant cells, then, migrate from the visceral pleural surface to the parietal pleural surface through pleural adhesions.
Another key mechanism for both paramalignant and MPEs is the impaired lymphatic drainage of the pleural space. The lymphatic system obstruction can occur in any location spreading from the stroma of the parietal pleura to the mediastinal and internal mammary lymph nodes. Pleural tumor invasion into the structures of the lymphatic system gives rise to an inflammatory response, thereby, leading to the increased microvascular permeability. ${ }^{[2]}$ In general, MPE is common in patients with EGFR mutations and anaplastic lymphoma kinase (ALK) fusion. ${ }^{[23,24]}$ EGFR or ALK mutations patients respond better to tyrosine kinase inhibitors (TKIs; gefitinib or erlotinib), and erlotinib penetrates the pleural cavity quite well. Therefore, these mutations should be tested in patients with MPE, as it is easy to detect the mutations and suggest guidelines. ${ }^{[1,25,26]}$

Based on all these data, we recommend the employment of IPC in case of a trapped lung and checking EGFR and ALK mutations in patients with adenocarcinoma, as it would change the course of treatment.

\section{Pleural effusion in malignant pleural mesothelioma}

A total of $90 \%$ of mesothelioma patients present with pleural effusion at the initial admission. Palliation is needed in patients with dyspnea and chest pain, and a tissue biopsy is usually required for diagnosis. Although mesothelioma patients do not have a precise predictor of pleurodesis results, pleurodesis is more likely to fail as long as the patient lives. A trapped lung is common in patients with mesothelioma, and IPCs are favorable alternatives. Pleurectomy/decortication and EPP are also among the treatment options. ${ }^{[1]}$

\section{Pleural metastases of thymomas}

Although thymomas rarely have distant metastases, $75 \%$ of recurrences occur in the pleura. The prognosis for thymoma pleural metastases is better than that for the pleural metastases of other primary tumors. Pleural implants can appear several years after both encapsulated and invasive thymoma resection, but pleural recurrences account for less than $10 \%$ of resected thymomas. They may be present following thymoma excision or as a result of tumor cell seeding during tumor manipulation, particularly if the mediastinal pleura has been opened. ${ }^{[27]}$

Five-year survival after R0 resection is 71 to $92 \%$, and an EPP, total pleurectomy or partial pleurectomy can be applied. The choice of surgical method usually depends on the extent of the tumor. To illustrate, if there are numerous nodular spreads in the parietal and 
visceral pleura and there are also pulmonary nodules, an EPP is recommended. In total pleurectomies, all parietal, mediastinal and diaphragmatic surfaces and the pericardium are removed, while a partial pleurectomy is recommended in mono- or oligometastatic disease. In all cases, neoadjuvant or adjuvant chemotherapy is recommended, and radiotherapy is also recommended if the surgical margin is positive or if there is residual disease.

In a previous study, Lucchi et al. ${ }^{[27]}$ evaluated 20 patients who underwent operations for thymoma and who were re-operated on for pleural metastases. Partial pleurectomies were performed in the area where the pleural implants were present, and if there was a wide pleural spread, a pleural catheter was inserted and intrapleural heated chemotherapy was applied. The results showed five- and 10-year survival rates of $43.1 \%$ and $25.8 \%$, respectively, after resection of the pleural metastases. The prognosis was worse for patients with diaphragmatic pleura, which was attributed to the fact that diaphragmatic involvement represents more advanced disease. The authors suggested that if multimodal therapy was applied, surgery should further improve the results.

The European Association of Thoracic Surgeons (ESTS) Thymic Working Group examined the role of surgical treatment for pleural metastases of thymic epithelial tumors in 152 patients who were operated in 12 different centers between 1977 and 2014. ${ }^{[28]}$ During the first intervention, $70.4 \%$ of the patients showed pleural involvement (Masaoka Stage IVA), while $29.6 \%$ had pleural metastases. The pleural metastases were caused by a thymoma in $88.8 \%$ and a thymic carcinoma in $11.2 \%$ patients. Extrapleural pneumonectomies were performed in 40 patients, total pleurectomies in 23 patients, and partial pleurectomy in 88 patients. The overall survival for the entire patient population was $96.4 \%, 91.0 \%$, $87.2 \%$ and $62.7 \%$ for one, three, five and 10 years, respectively, and there was no significant difference between relapse-free survival and total survival for EPP, total pleurectomy or partial pleurectomy patients. Compared to thymomas, thymic carcinomas were found to affect overall survival and relapsefree survival, and total survival was worse in those with an incomplete resection. Patients who underwent surgical treatment for subsequent pleural metastases had better overall survival than those with pleural metastases (Masaoka Stage IVA) during the first operation. This was attributed to the more aggressive tumor biology of patients with initial pleural involvement. ${ }^{[28]}$ As a result, no matter which surgical method is chosen, complete resection remains the basis of treatment in thymic epithelial tumors with pleural involvement. Fiorelli et al. ${ }^{[29]}$ and Wright $^{[30]}$ achieved better survival in patients with recurrent resection, if they were able to perform complete resection. Similar to the treatment of malignant pleural mesothelioma, some authors added hyperthermic intrapleural chemotherapy to the surgical resection of pleural recurrences from thymomas. ${ }^{[27]}$

\section{Breast cancer and malignant pleural effusion}

The probability of breast cancer patients developing MPE can be up to 25\%, and unilateral and bilateral effusions can be seen. Median survival depends on systematic treatment response, and the average survival after pleural fluid accumulation due to breast cancer metastases is about 15 months. Palliative methods such as recurrent thoracentesis, permanent pleural catheter or talc pleurodesis are among the commonly used treatment methods in patients with a poor prognosis. These procedures improve respiratory function by providing symptomatic relief from dyspnea through continuous fluid drainage. Martini et al. ${ }^{[3]}$ achieved the best survival rates for breast cancer in various patient groups who underwent pleurectomy for MPE. Therefore, pleurectomies can be recommended for breast cancer patients with MPE..$^{[1,2,31,32]}$

\section{Renal cell carcinoma (RCC) and malignant pleural effusion}

Renal cell carcinomas constitute only 1 to $2 \%$ of all malignancy-related pleural effusions. In these patients, most of the pleural metastases are related to metastatic lesions developing in the lung. Solitary pleural metastases having no lung metastases are rare phenomena. A possible explanation for isolated pleural metastases is the hematogenous spread through the Batson venous plexus, which is a network of valveless veins that surrounds the spinal cord and vertebral column and is connected to the azygos vein, hemiazygos vein, bronchial vein and intercostal veins. Malignant effusions due to RCCs occur more frequently in patients having papillary and clear cell tumors, and these tumors tend to be high grade. Development of spontaneous hemothorax has been detected in a patient with an RCC resulting from metastatic involvement and invasion of the intercostal vessels. ${ }^{[33-36]}$ To date, surgery is most commonly preferred for localized metastases, as there is no effective chemotherapy for RCCs other than interferon therapy. ${ }^{[33-36]}$ 


\section{Lymphoproliferative diseases and malignant pleural effusion}

Lymphomas present with pleural effusion in 20 to $30 \%$ of patients, and pleural effusion is rarely encountered in leukemia and multiple myeloma. ${ }^{[36]}$ Hodgkin and non-Hodgkin lymphomas often cause MPE through different mechanisms: while Hodgkin's disease results in MPE due to lymphatic obstruction, in non-Hodgkin lymphoma, MPE is likely to originate from a combination of lymphatic obstruction and direct pleural invasion. Less than $10 \%$ of lymphomarelated pleural effusions are chylothoraces.

Although lymphomas are highly chemosensitive tumors, pleural procedures are required in approximately $37.5 \%$ of patients (pleurodesis and/or tunneled pleural catheter). Primary pleural lymphoma, although rare, comprises two main types: primary effusion lymphoma and pyothoraxassociated lymphoma. ${ }^{[1,38]}$ Pulmonary effusion has been found to be an insufficient prognostic factor in lymphoma. Systematic chemotherapy is the preferred form of treatment; however, in case of mediastinal involvement, mediastinal radiotherapy is also administered.

If chylothorax occurs, conservative treatment is usually performed with low-fat, medium-chain triglyceride-supported regimens, or a tube thoracostomy with total parenteral nutrition to reduce recurrence. Pleural effusions secondary to lymphoma may respond to chemotherapy, but if they fail, pleurodesis or an IPC should be considered. The VATS is performed for refractory chylothoraces that do not respond to treatment, allowing for sufficient drainage from the thoracic cavity and simultaneous pleurodesis can also be provided. ${ }^{[1]}$

\section{Ovarian Cancer and malignant pleural effusion}

Ovarian cancer affects one out of every 70 women. The pleura is the most prevalent extra-abdominal metastatic location in ovarian cancer patients, and it is the most common extra-abdominal metastatic site. Cytoreductive surgery and adjuvant therapy are the standard treatments for advanced stage ovarian cancer. Pleural effusions are thought to be present in more than one-third of individuals with Stage IV ovarian cancer. ${ }^{[1-39]}$ Many MPE patients are examined with computed tomography scans to determine whether bulky thoracic disease prevents abdominal surgical cytoreduction. However, it is uncertain whether radiographic scans alone can provide an appropriate evaluation of intrathoracic illness and the amount of diaphragmatic pleural involvement.
The presence of macroscopic intrathoracic disease may change the patient's therapy, particularly if unresected $>1$ to $2 \mathrm{~cm}$ intrathoracic tumor deposits would result in unsatisfactory residual disease at the end of maximum intra-abdominal cytoreduction. The VATS can detect the pleural tumor burden, allow intrathoracic cytoreduction and, sometimes, reveal gross tumor residue in the pleural cavity and that abdominal surgery is unnecessary. ${ }^{[1,39,40]}$

Eisenkop ${ }^{[40]}$ investigated the predicted advantages of thoracoscopies as a treatment strategy for Stage IIIC-IV epithelial ovarian cancer by performing VATS simultaneously with primary cytoreduction in 30 patients for detecting intrathoracic disease and the possibility of cytoreduction. The survival rates for patients categorized in Stage IV undergoing a thoracoscopy was found to be longer than the ones who did not. Thoracoscopies can be used to evaluate the degree of intrathoracic disease and, in rare cases, to perform full cytoreduction. Given that the size of the greatest residual illness at the time of cytoreductive surgery affects survival independently, occult residual intrathoracic disease that is greater than the largest recognized intra-abdominal residual disease may possibly reduce survival. Eisenkop ${ }^{[40]}$ argued that thoracoscopies were linked with a low morbidity risk.

Some authors have advocated transdiaphragmatic thoracoscopies with minimal operation time with a small diaphragmatic incision. ${ }^{[40]}$ Although viewing both pleural and pulmonary surfaces is impossible, transdiaphragmatic thoracoscopies allow for adequate vision and, if necessary, ablation or excision of large pleural implants by diaphragmatic incision extension. Although the transdiaphragmatic approach is faster than a procedure through the chest wall, a thoracic surgeon performing the thoracoscopy through the chest wall may be preferable in certain patients, such as when intrathoracic findings are expected to preclude intra-abdominal cytoreduction or when more extensive intrathoracic surgery is planned..$^{[41]}$

Evaluation of pleural metastases is of particular importance, as most ovarian cancers are advanced stage and the pleura is the most common extra-abdominal metastatic site. We recommend performing VATS for every patient to detect pleural metastases, as they would change the course of treatment.

\section{Rare primary tumors of the pleura}

Primary sarcomas can occur in the pleural cavity. Although differential diagnosis can be challenging, immunohistochemistry and ultrastructural and 
molecular examinations can be helpful for the accurate diagnosis for most spindle cell tumors of the pleural cavity. As most of these neoplasms require distinct treatment methods and different prognoses, an accurate diagnosis is of utmost importance. They are difficult to treat, but similar principles apply to most: localized tumors require complete excision with large margins (usually $2 \mathrm{~cm}$ ), and adjuvant chemotherapy and radiotherapy are recommended for insufficient margins or incomplete resection. ${ }^{[1,2]}$

In conclusion, the treatment approach for malignant pleural effusions caused by pleural metastases depends on the patient's performance, tumor type, and expected survival. Recurrent thoracentesis may be a good option for patients with survival times less than 45 days. Pleurectomy via video-assisted thoracic surgery or thoracotomy may constitute an option in pleural metastases of breast cancer, ovarian cancer and, even extrapleural pneumonectomy can be considered in thymoma pleural metastases.

\section{Declaration of conflicting interests}

The authors declared no conflicts of interest with respect to the authorship and/or publication of this article.

\section{Funding}

The authors received no financial support for the research and/or authorship of this article.

\section{REFERENCES}

1. Thomas R, Kalomenidis I, Jett J, Gary Lee YC. Effusion from malignant causes. In: Light RW, Gary Lee YC, editors. Textbook of pleural diseases. New York: Taylor \& Francis Group, LLC; 2016. p. 278-94.

2. Hudson JL, Puri V. Malignant pleural effusions. In: LoCicero J, Feins RH, Colson YL, Rocco G, editors. General thoracic surgery. Philadelphia: Wolters Kluwer; 2019. p. 8242-366.

3. Rodrîguez-Panadero F, Borderas Naranjo F, López Mejîas J. Pleural metastatic tumours and effusions. Frequency and pathogenic mechanisms in a post-mortem series. Eur Respir J 1989;2:366-9.

4. Özdemir E. Plevra ve plevral sıvının fizyolojisi. In: Şahin E, Karadayı Ş, Katrancıoğlu Ö, editörler. Her yönüyle plevra ve hastalıkları. Sivas: Cumhuriyet Üniversitesi Yayınları; 2018. s. 35-47.

5. Miserocci G, Beretta E, Grasso GS. Mechanics and fluid dynamics of lung and pleural space. In: LoCicero J, Feins RH, Colson YL, Rocco G, editors. General thoracic surgery. Philadelphia: Wolters Kluwer; 2019. p.7158-223.

6. Pilling JE, Dusmet ME, Ladas G, Goldstraw P. Prognostic factors for survival after surgical palliation of malignant pleural effusion. J Thorac Oncol 2010;5:1544-50.

7. Clive AO, Kahan BC, Hooper CE, Bhatnagar R, Morley AJ, Zahan-Evans N, et al. Predicting survival in malignant pleural effusion: Development and validation of the LENT prognostic score. Thorax 2014;69:1098-104.

8. Kara M, Alzafer S, Okur E, Halezeroglu S. The use of single incision thoracoscopic pleurectomy in the management of malignant pleural effusion. Acta Chir Belg 2013;113:270-4.

9. Çelik B, Demircan S, Bek Y, Başoğlu A . Malign plevral effüzyonda farklı plörodezis yöntemleri ile talk ve oksitetrasiklinin karşılaştırılması. Turkish J Thorac Cardiovasc Surg 2004;12:172-9.

10. Dresler CM, Olak J, Herndon JE 2nd, Richards WG, Scalzetti E, Fleishman SB, et al. Phase III intergroup study of talc poudrage vs talc slurry sclerosis for malignant pleural effusion. Chest 2005;127:909-15.

11. Fysh ET, Tan SK, Read CA, Lee F, McKenzie K, Olsen N, et al. Pleurodesis outcome in malignant pleural mesothelioma. Thorax 2013;68:594-6.

12. Viallat JR, Rey F, Astoul P, Boutin C. Thoracoscopic talc poudrage pleurodesis for malignant effusions. A review of 360 cases. Chest 1996;110:1387-93.

13. Davies HE, Mishra EK, Kahan BC, Wrightson JM, Stanton AE, Guhan A, et al. Effect of an indwelling pleural catheter vs chest tube and talc pleurodesis for relieving dyspnea in patients with malignant pleural effusion: The TIME2 randomized controlled trial. JAMA 2012;307:2383-9.

14. Putnam JB Jr, Light RW, Rodriguez RM, Ponn R, Olak J, Pollak JS, et al. A randomized comparison of indwelling pleural catheter and doxycycline pleurodesis in the management of malignant pleural effusions. Cancer 1999;86:1992-9.

15. Tremblay A, Michaud G. Single-center experience with 250 tunnelled pleural catheter insertions for malignant pleural effusion. Chest 2006;129:362-8.

16. Van Meter ME, McKee KY, Kohlwes RJ. Efficacy and safety of tunneled pleural catheters in adults with malignant pleural effusions: A systematic review. J Gen Intern Med 2011;26:70-6.

17. Fysh ETH, Tremblay A, Feller-Kopman D, Mishra EK, Slade M, Garske L, et al. Clinical outcomes of indwelling pleural catheter-related pleural infections: An international multicenter study. Chest 2013;144:1597-602.

18. Little AG, Kadowaki MH, Ferguson MK, Staszek VM, Skinner DB. Pleuro-peritoneal shunting. Alternative therapy for pleural effusions. Ann Surg 1988;208:443-50.

19. Genc O, Petrou M, Ladas G, Goldstraw P. The long-term morbidity of pleuroperitoneal shunts in the management of recurrent malignant effusions. Eur J Cardiothorac Surg 2000;18:143-6.

20. Naito T, Satoh H, Ishikawa H, Yamashita YT, Kamma $\mathrm{H}$, Takahashi $\mathrm{H}$, et al. Pleural effusion as a significant prognostic factor in non-small cell lung cancer. Anticancer Res 1997;17:4743-6.

21. Postmus PE, Brambilla E, Chansky K, Crowley J, Goldstraw P, Patz EF Jr, et al. The IASLC Lung Cancer Staging Project: Proposals for revision of the $\mathrm{M}$ descriptors in the forthcoming (seventh) edition of the TNM classification of lung cancer. J Thorac Oncol 2007;2:686-93.

22. Morgensztern D, Waqar S, Subramanian J, Trinkaus K, Govindan R. Prognostic impact of malignant pleural effusion at presentation in patients with metastatic non-small-cell lung cancer. J Thorac Oncol 2012;7:1485-9. 
23. Wu SG, Yu CJ, Tsai MF, Liao WY, Yang CH, Jan IS, et al. Survival of lung adenocarcinoma patients with malignant pleural effusion. Eur Respir J 2013;41:1409-18.

24. Doebele RC, Lu X, Sumey C, Maxson DA, Weickhardt $\mathrm{AJ}$, Oton $\mathrm{AB}$, et al. Oncogene status predicts patterns of metastatic spread in treatment-naive nonsmall cell lung cancer. Cancer 2012;118:4502-11.

25. Travis WD, Brambilla E, Noguchi M, Nicholson AG, Geisinger KR, Yatabe Y, et al. International Association for the Study of Lung Cancer/American Thoracic Society/ European Respiratory Society international multidisciplinary classification of lung adenocarcinoma. J Thorac Oncol 2011;6:244-85.

26. Lindeman NI, Cagle PT, Beasley MB, Chitale DA, Dacic S, Giaccone $\mathrm{G}$, et al. Molecular testing guideline for selection of lung cancer patients for EGFR and ALK tyrosine kinase inhibitors: Guideline from the College of American Pathologists, International Association for the Study of Lung Cancer, and Association for Molecular Pathology. J Thorac Oncol 2013;8:823-59.

27. Lucchi M, Davini F, Ricciardi R, Duranti L, Boldrini L, Palmiero G, et al. Management of pleural recurrence after curative resection of thymoma. J Thorac Cardiovasc Surg 2009;137:1185-9.

28. Moser B, Fadel E, Fabre D, Keshavjee S, de Perrot M, Thomas P, et al. Surgical therapy of thymic tumours with pleural involvement: An ESTS Thymic Working Group Project. Eur J Cardiothorac Surg 2017;52:346-55.

29. Fiorelli A, D'Andrilli A, Vanni C, Cascone R, Anile M, Diso $\mathrm{D}$, et al. Iterative surgical treatment for repeated recurrences after complete resection of thymic tumors. Ann Thorac Surg 2017;103:422-31.

30. Wright CD. Pleuropneumonectomy for the treatment of Masaoka stage IVA thymoma. Ann Thorac Surg 2006;82:1234-9.

31. Martini N, Bains MS, Beattie EJ Jr. Indications for pleurectomy in malignant effusion. Cancer 1975;35:734-8.
32. Rawindraraj AD, Zhou CY, Pathak V. Delayed breast cancer relapse with pleural metastasis and malignant pleural effusion after long periods of disease-free survival. Respirol Case Rep 2018;6:e00375.

33. Agrawal A, Sahni S, Iftikhar A, Talwar A. Pulmonary manifestations of renal cell carcinoma. Respir Med 2015;109:1505-8.

34. Renshaw AA, Comiter CV, Nappi D, Granter SR. Effusion cytology of renal cell carcinoma. Cancer 1998;84:148-52.

35. Kataoka M, Yata Y, Nose S, Yasuda K, Ohara T. Solitary pleural metastasis from renal cell carcinoma: A case of successful resection. Surg Case Rep 2015;1:36.

36. Bettenhausen A, Hamaji M, Burt BM, Ali SO. Pleurectomy and decortication for metastatic renal cell carcinoma. J Thorac Cardiovasc Surg 2015;150:e3-5.

37. Alexandrakis MG, Passam FH, Kyriakou DS, Bouros D. Pleural effusions in hematologic malignancies. Chest 2004;125:1546-55.

38. Hirai S, Hamanaka Y, Mitsui N, Morifuji K, Sutoh M. Primary malignant lymphoma arising in the pleura without preceding long-standing pyothorax. Ann Thorac Cardiovasc Surg 2004;10:297-300.

39. Diaz JP, Abu-Rustum NR, Sonoda Y, Downey RJ, Park BJ, Flores RM, et al. Video-assisted thoracic surgery (VATS) evaluation of pleural effusions in patients with newly diagnosed advanced ovarian carcinoma can influence the primary management choice for these patients. Gynecol Oncol 2010;116:483-8.

40. Eisenkop SM. Thoracoscopy for the management of advanced epithelial ovarian cancer--a preliminary report. Gynecol Oncol 2002;84:315-20.

41. Terauchi F, Kobayashi Y, Nagashima T, Moritake T, Nishi H, Fujito A, et al.Pilotstudy on transdiaphragmaticthoracoscopicassisted pleural biopsy and intrathoracic washing cytology for Stage IIIc ovarian cancer with diaphragmatic metastases. Int J Gynecol Cancer 2009;19:300-3. 